\title{
The effects of Nigella Sativa extract on renal tissue oxidative damage during neonatal and juvenile growth in propylthiouracil-induced hypothyroid rats
}

\author{
${ }^{1}$ Mohebbati R, ${ }^{1,2}$ Hosseini M, ${ }^{2}$ Haghshenas M, ${ }^{3}$ Nazariborun A, ${ }^{1}$ Beheshti F \\ ${ }^{1}$ Neurogenic Inflammation Research Center, School of Medicine, Mashhad University of Medical Sciences, \\ Mashhad, Iran; ${ }^{2}$ Division of Neurocognitive Sciences, Psychiatry and Behavioral Sciences Research Center, \\ Mashhad University of Medical Sciences, Mashhad, Iran; ${ }^{3}$ Department of Physiology, School of Medicine, \\ Zabol University of Medical Sciences, Zabol, Iran \\ E-mail: beheshtif931@mums.ac.ir
}

Objective. We investigated the effects of hydroalcoholic extract of Nigella sativa (NS) on renal tissue oxidative damage associated with propylthiouracil (PTU)-induced hypothyroidism during neonatal and juvenile growth in rats.

Methods. Pregnant rats were divided into five groups designated as: 1) control; 2) propylthiouracil (PTU); 3) PTU-NS100; 4) PTU-NS200, and 5) PTU-NS400. All mothers except the control group received $0.005 \%$ PTU in their drinking water during lactation. Besides PTU, mothers in groups 3-5 received 100, 200, and $400 \mathrm{mg} / \mathrm{kg}$ of NS extract. After lactation period, the offspring continued to receive the same experimental treatment for the first 8 weeks of their life. Ten male offsprings of each group were randomly selected, blood samples collected, and the kidney tissues removed.

Results. The serum thyroxin concentration in PTU group was lower than control group and improved by extract. PTU increased the renal malondialdehyde (MDA), while reduced the total thiols concentrations and catalase (CAT) and superoxide dismutase (SOD) activity compared to control group. Administration of 200 and $400 \mathrm{mg} / \mathrm{kg}$ of NS extract decreased MDA level, while it increased the total thiols and $400 \mathrm{mg} / \mathrm{kg}$ increased CAT and SOD activity in renal tissues compared to PTU group. Serum creatinine and blood urea nitrogen (BUN) in PTU group was higher than in comparison with the control group. $400 \mathrm{mg} / \mathrm{kg}$ decreased creatinine, but both 200 and $400 \mathrm{mg} / \mathrm{kg}$ improved BUN concentration compared to PTU group.

Conclusion. The results of this study demonstrate that the hydroalcoholic extract of NS has a protective effect on the renal tissue oxidative damage associated with PTU-induced hypothyroidism during neonatal and juvenile growth in rats.

Key words: hypothyroidism, Nigella sativa, oxidative damage, propylthiouracil, renal

Hyperthyroidism and thyrotoxicosis belong to diseases that need a long duration of continuous therapy of thioamide anti-thyroid drugs such as propylthiouracil (PTU). Adverse reactions to PTU are uncommon, occurring in $1-5 \%$ of the patients (Cooper 1984). PTU exerts its anti-thyroid effects through inhibiting the iodine oxidation and ionization of the monoiodotyrosine, preventing the coupling stage in the process of thyroxin production, and inhibition of the peripheral conversion of thyroxin (T4) into triiodothyronine (T3) (Fumarola et al. 2010). Mild leukopenia, fever, rash, and arthralgia are the common

Corresponding author: Farimah Beheshti, PhD. student, Neurocognitive Research Center and Department of Physiology, School of Medicine, Azadi Square, Mashhad, Iran; phone: 98-51-38828565; fax: 98-51-38828564; e-mail: beheshtif931@mums.ac.ir, 
side effects. However, more serious reactions including agranulocytosis, hepatitis, vasculitis, a lupus-like syndrome, and acute interstitial nephritis with acute renal failure have also been reported (Reinhart et al. 1994). It has been reported that chronic therapy with PTU is associated with drug-induced tubuleinterstitial nephritis with renal failure (Nakahama et al. 1999). In addition, PTU therapy may cause diffuse proliferative lupus nephritis via altering the immunological responses (Prasad et al. 1997).

It is well known that PTU induces a hypothyroidism status (Sener et al. 2006). Thyroid hormones have critical in the regulation of the energy metabolism, mitochondrial activity, oxygen consumption, and active oxygen metabolism (Katyare et al. 1994; Martinez et al. 2001). Hypothyroidism induces a hypodynamic state of the circulatory system, which would result in decrease of renal functions and particularly of the glomerular filtration rate (Moses and Scheinman 1996). Several hemodynamic changes have been reported in hypothyroidism that may influence the renal function, such as hyponatremia, decrease in renal blood flow, and renal plasma flow, which may decrease the glomerular filtration rate (Derubertis et al. 1971). Hypothyroidism induced by PTU has been reported to be accompanied by a renal toxicity and an increased level of malondialdehyde (MDA) in renal tissues (Sarandol et al. 2005). Serum T4 concentration in patients with chronic renal failure has been reported to be lower than in control group and was accompanied with renal oxidative damage (Singh et al. 2006).

There are some natural products, such as Nigella sativa (NS), which have been shown to be protective in some situations associated with the neuronal damage (Kanter 2008). In traditional medicine, NS is frequently used as a healing medicine for treatment of various diseases, such as asthma, headache, dysentery, infections, obesity, back pain, hypertension, and gastrointestinal problems. The major bio-actives of NS seeds are thymoquinone (TQ), alkaloids (nigellidine, nigellimine, and nigellicine), vitamin-like thiamine, riboflavin, pyridoxine, niacin, folic acid, minerals, and proteins (Salem 2005). Recently, clini$\mathrm{cal}$ and experimental studies have confirmed many therapeutic effects of NS extracts, including relaxant (Boskabady et al. 2004; Boskabady et al. 2008), immunomodulative (El-Kadi and Kandil 1987), anti-inflammatory (Houghton et al. 1995; Keyhanmanesh et al. 2010), antitumor (El Daly 1998), antidiabetic (AlHader et al. 1993), and antiulcerogenic (El-Dakhakhny et al. 2002) effects. NS have protective effects on potassium bromated-induced renal oxidative stress by decreasing lipid peroxidation (Khan et al. 2003). Moreover, modern toxicological studies have demonstrated that crude extracts of the seeds and some of its active constituents (volatile oil, TQ) might have a protective effect against nephrotoxicity and hepatotoxicity induced by either the disease or chemicals (Ali and Blunden 2003).

Thus, the objective of this study was to elucidate the effects of hydro-alcoholic extract of NS on hypothyroidism-associated renal tissues oxidative damage during neonatal and juvenile growth in rats.

\section{Material and Methods}

Animals and treatments. Thirty pregnant female Wistar rats (12 week-old and weighing 220-250 g) were kept in separate cages at $22 \pm 2^{\circ} \mathrm{C}$ in a room with a $12 \mathrm{~h}$ light/dark cycle (light on at 7:00 am). Animals were randomly divided into six groups including: 1) control; 2) propylthiouracil (PTU); 3) PTU-NS 100; 4) PTU-NS 200 and 5) PTU-NS 400. Rats in the control group received normal drinking water, whereas the second group received drinking water supplemented with $0.005 \%$ PTU (Sigma, USA) to develop hypothyroidism (Hosseini et al. 2010). Groups 3,4, and 5 received drinking water supplemented with $0.005 \%$ PTU and 100, 200 and $400 \mathrm{mg}$ hydro-alcoholic extract of NS per kilogram body weight respectively (Hadjzadeh et al. 2007; Javanbakht et al. 2013). Mothers received the experimental treatments from the first day after delivery through the lactation period and after that the offspring continued to receive the experimental treatments in their drinking water for the first two months of their life.

Finally, ten male offsprings of each group were randomly selected and they deeply anesthetized. The blood samples were collected for thyroxin assessment and renal damage parameters. The left kidneys were also obtained for biochemical measurements. To confirm the hypothyroidism, the serum thyroxin levels were assessed using the radioimmunoassay method. Animal handling and all related procedures were carried out in accordance with the procedures approved by the Mashhad University of Medical Sciences Ethical Committee.

Extract preparation. NS seeds were purchased from a local market in Mashhad, Iran. They were powdered $(100 \mathrm{~g})$ NS and extracted in a Soxhlet apparatus with ethanol (70\%). The resulted solution was concentrated under reduced pressure. The extract was kept in a refrigerator and at $-20^{\circ} \mathrm{C}$.

Biochemical assessment. Serum blood urea nitrogen (BUN) and creatinine levels were measured by 
creatinine and BUN kits (Pars Azmoon Company, Tehran, Iran).

Total thiols groups were measured using 2,2'-dinitro-5,5'-dithiodibenzoic acid (DTNB), a reagent that reacts with the $\mathrm{SH}$ groups and produces a yellow colored complex which has a peak absorbance at 412 $\mathrm{nm}$ (Ellman 1959). Briefly, $1 \mathrm{ml}$ Tris-ethylenediaminetetraacetic acid (EDTA) buffer ( $\mathrm{pH} \mathrm{8.6)} \mathrm{was} \mathrm{added}$ to $50 \mu \mathrm{l}$ kidney homogenate in $1 \mathrm{ml}$ cuvettes and the absorbance was read at $412 \mathrm{~nm}$ against Tris-EDTA buffer (A1). Then $20 \mu \mathrm{l}$ DTNB reagents $(10 \mathrm{mM}$ in methanol) were added to the mixture and after 15 min incubation in room temperature, the absorbance was measured again (A2). The absorbance of DTNB reagent was estimated as a blank (B). Total thiols concentration $(\mathrm{mM})$ was calculated based on an equation previously described by Hosseini et al. (2012; Khodabandehloo et al. 2013).

Malondialdehyde (MDA) levels, as an index of lipid peroxidation, were measured in cortical and hippocampal tissues. MDA reacts with thiobarbituric acid (TBA) as a thiobarbituric acid reactive substance (TBARS) and produces a red colored complex which has a peak absorbance at $535 \mathrm{~nm} .2 \mathrm{ml} \mathrm{TBA} /$ trichlorooacetic acid (TCA)/ hydrochloric acid (HCL) reagent was added to $1 \mathrm{ml}$ homogenate and the solution was incubated in a boiling water bath for $40 \mathrm{~min}$. After cooling, the whole solutions were centrifuged (1000 g, $10 \mathrm{~min})$. The absorbance of supernatant was measured at $535 \mathrm{~nm}$. The MDA concentration (C) was calculated as follows (Hosseini et al. 2012; Khodabandehloo et al. 2013)

$$
\mathrm{C}(\mathrm{m})=\text { Absorbance } /\left(1.65 \times 10^{5}\right) \text {. }
$$

Catalase (CAT) activity was estimated using the method of Aebi (1983). The principle of the assay is based on determination of the rate constant, $\mathrm{k}$, ( $\mathrm{di}$ mension: $\mathrm{s}-1, \mathrm{k}$ ) of hydrogen peroxide decomposition. By measuring the decrease in absorbance at 240 $\mathrm{nm}$ per minute, the rate constant of the enzyme was determined. Activities were expressed as k (rate constant) per liter.

Superoxide dismutase (SOD) activity was measured by the procedure described by Madesh and Balasubramanian (1998). A colorimetric assay involving generation of superoxide by pyrogallol auto-oxidation and the inhibition of superoxide-dependent reduction of the tetrazolium dye, MTT [3-(4,5-dimethylthiazol-2-yl) 2,5-diphenyltetrazolium bromide] to its formazan by SOD was measured at $570 \mathrm{~nm}$. One unit of SOD activity was defined as the amount of enzyme causing 50\% inhibition in the MTT reduction rate.
Statistical analysis. All data were expressed as means \pm SEM. The data were compared by one-way ANOVA followed by Tukey's post hoc comparisons test. Differences were considered statistically significant when $\mathrm{p}<0.05$.

\section{Results}

The serum T4 concentrationinPTU-treated animals was significantly lower compared to that in control animals ( $<<0.001$; Table 1). Treatment with all three doses of the NS extract significantly attenuated the PTUinduced reduction in serum T4 $(\mathrm{p}<0.001$; Table 1$)$.

Additionally, the PTU exposure influenced both MDA and thiols concentrations in the renal tissues. PTU increased renal MDA ( $\mathrm{p}<0.001$; Figures 1$)$ compared to control group, while reduced the thiols concentrations in renal tissues $(\mathrm{p}<0.001$; Figure 2$)$ compared to control group. Treatment of the animals with 200 and $400 \mathrm{mg} / \mathrm{kg}$ of NS extract resulted in a decreased level of MDA in renal tissues compared to PTU group ( $\mathrm{p}<0.05$; Figure 1). In addition, treatment of the animals with 200 and $400 \mathrm{mg} / \mathrm{kg}$ NS extract significantly improved the renal levels of total thiols compared to PTU group ( $\mathrm{p}<0.05$, Figure 2$)$.

CAT concentration of renal tissues in PTU group was lower than in control group ( $<<0.001$; Figure 3$)$. Animals in all NS-treated groups showed an increased level of the CAT concentration in renal tissues compared to PTU group ( $<<0.05-\mathrm{p}<0.001$; Figure 3 ).

SOD concentration of renal tissues in PTU group was lower than control group ( $\mathrm{p}<0.001$; Figure 4$)$. The animals in PTU-NS400 group showed a significant increase in the concentration of SOD in the renal tissues compared to PTU group ( $<<0.05$; Figure 4).

Table 1

Serum thyroxin concentrations in offspring.

\begin{tabular}{lc}
\hline Group & $\mathrm{T} 4(\mu \mathrm{g} / \mathrm{dl})$ \\
\hline Control & 7.8 \\
PTU & $3.9^{* * *}$ \\
PTU-NS100 & $6.1^{+++}$ \\
PTU-NS200 & $6.1^{+++}$ \\
PTU-NS400 & $6.3^{+++}$ \\
\hline
\end{tabular}

Data are presented as mean $\pm \operatorname{SEM}(n=10) .{ }^{* * *} \mathrm{p}<0.001$ vs. control group, ${ }^{++} \mathrm{p}<0.001$ vs. PTU group

PTU - propylthiouracil-treated rats; PTU-NS100/200/400 - rats treated with propylthiouracil and Nigella sativa extract (100, 200 and $400 \mathrm{mg} / \mathrm{kg}$ ) 


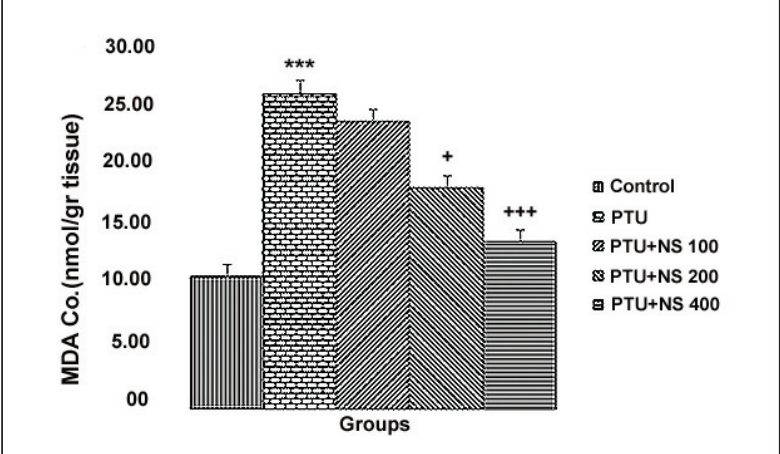

Figure 1. The concentrations of malondialdehyde (MDA) in renal tissues. Data are presented as mean \pm SEM. $(n=10)$. ${ }^{* * *} \mathrm{p}<0.001$ vs. control group, ${ }^{++} \mathrm{p}<0.01,{ }^{+++} \mathrm{p}<0.001$ vs. PTU group; PTU - propylthiouracil-treated rats; PTUNS100/200/400 - rats treated with propylthiouracil and Nigella sativa extract (100, 200 and $400 \mathrm{mg} / \mathrm{kg})$.

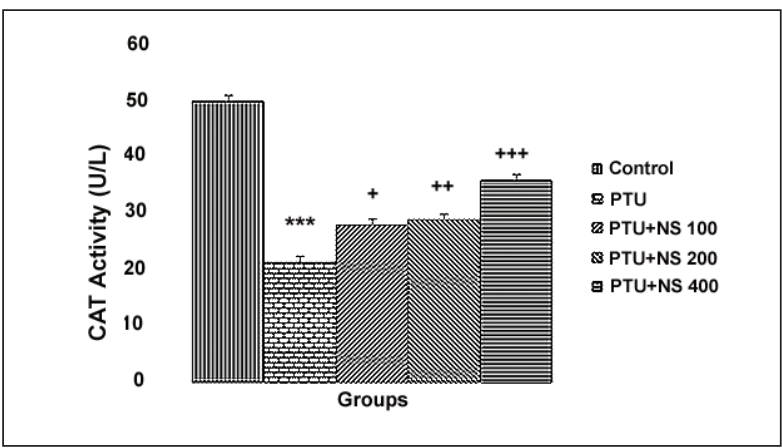

Figure 3. The catalase (CAT) activity in renal tissues. Data are presented as mean $\pm \operatorname{SEM}(n=10) .{ }^{* *} \mathrm{p}<0.001$ vs. control group, ${ }^{++} \mathrm{p}<0.01,{ }^{++} \mathrm{p}<0.01$ and ${ }^{++} \mathrm{P}<0.001$ vs. PTU group; PTU - propylthiouracil-treated rats; PTU-NS100/200/400 rats treated with propylthiouracil and Nigella sativa extract $(100,200$ and $400 \mathrm{mg} / \mathrm{kg})$.

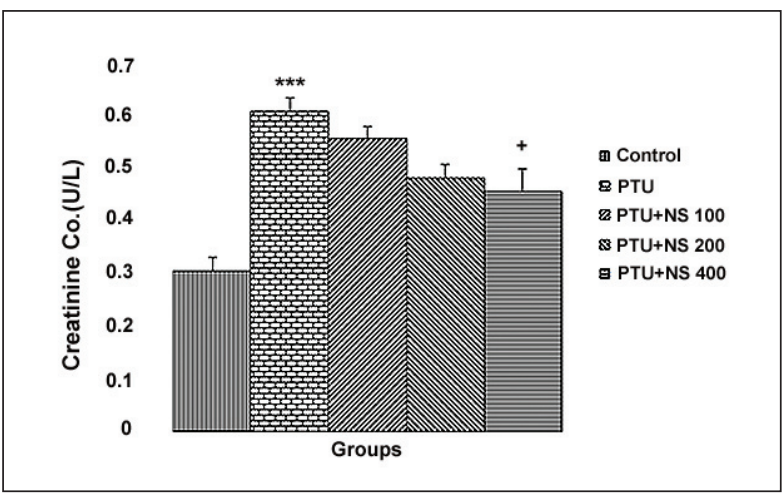

Figure 5. The creatinine concentration in serum.

Data are presented as mean $\pm \operatorname{SEM}(n=10) .{ }^{* *} \mathrm{p}<0.001$ vs. control group, ${ }^{+} \mathrm{p}<0.05$ vs. PTU group; PTU - propylthiouraciltreated rats; PTU-NS100/200/400 - rats treated with propylthiouracil and Nigella sativa extract (100, 200 and $400 \mathrm{mg} / \mathrm{kg})$.

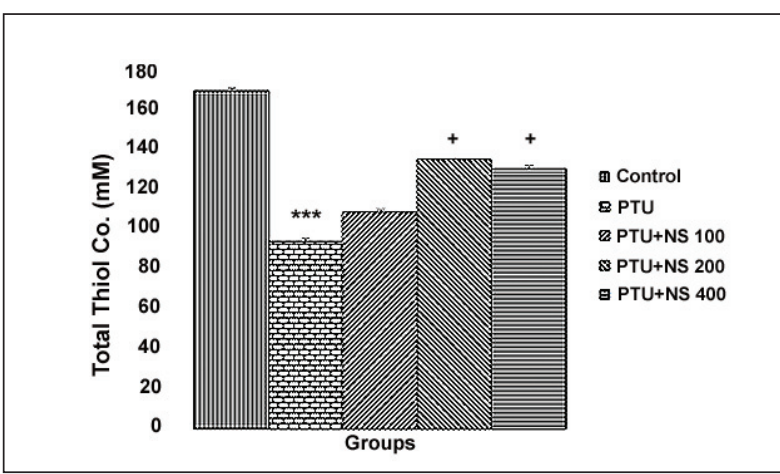

Figure 2. The total thiols concentrations in renal tissues.

Data are presented as mean $\pm \operatorname{SEM}(n=10) .{ }^{* * *} \mathrm{p}<0.001$ vs. control group, ${ }^{+} \mathrm{p}<0.05$ vs. PTU group; PTU - propylthiouraciltreated rats; PTU-NS100/200/400 - rats treated with propylthiouracil and Nigella sativa extract (100, 200 and $400 \mathrm{mg} / \mathrm{kg}$ ).

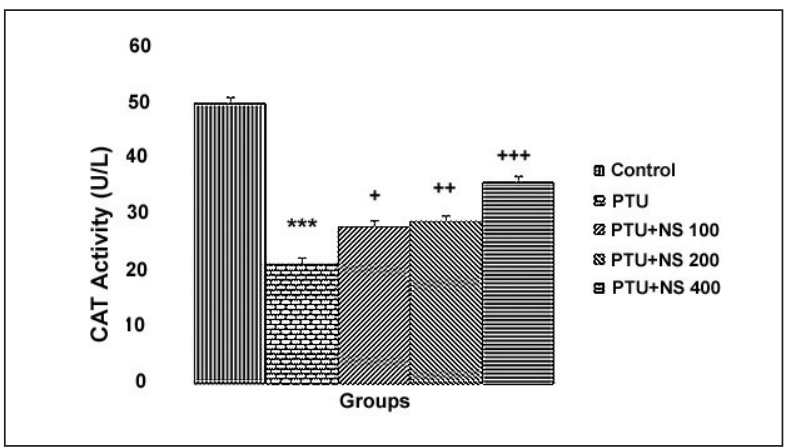

Figure 4. The superoxide dismutase (SOD) activity in renal tissues. Data are presented as mean \pm SEM. $(n=10) .{ }^{* * *} p<0.001$ vs. control group, ${ }^{+} \mathrm{p}<0.05$ vs. PTU group; PTU - propylthiouraciltreated rats; PTU-NS100/200/400 - rats treated with propylthiouracil and Nigella sativa extract (100, 200 and $400 \mathrm{mg} / \mathrm{kg})$.

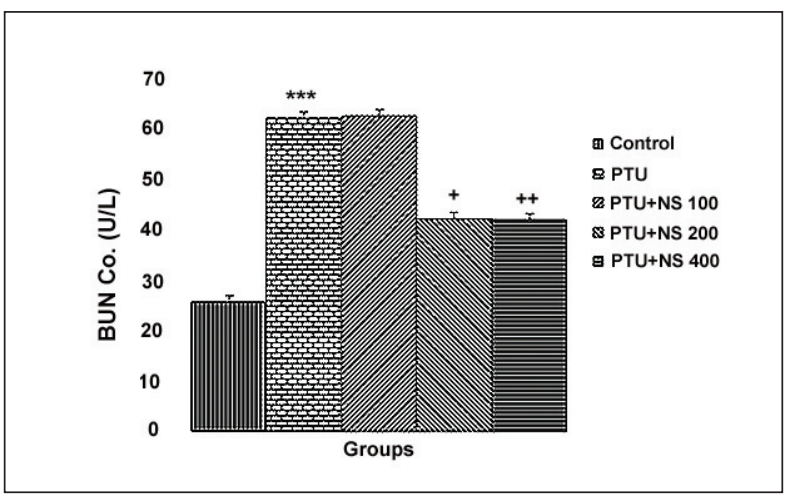

Figure 6. The blood urea nitrogen (BUN) concentration in serum. Data are presented as mean $\pm \operatorname{SEM}(n=10)$. ${ }^{* *} \mathrm{p}<0.001$ vs. control group, ${ }^{+} \mathrm{p}<0.05$ and ${ }^{++} \mathrm{P}<0.001$ vs. $\mathrm{PTU}$ group; PTU - propylthiouracil-treated rats; PTU-NS100/200/400 rats treated with propylthiouracil and Nigella sativa extract $(100,200$ and $400 \mathrm{mg} / \mathrm{kg})$. 
Serum creatinine in PTU group was higher than control group ( $<0.001$; Figure 5). Treatment with 400 $\mathrm{mg} / \mathrm{kg}$ of NS extract decreased serum creatinine concentration compared to PTU group ( $p<0.05$; Figure 5).

BUN in serum of the PTU group was higher than in the control group ( $<<0.001$; Figure 6$)$. Treatment with 200 and $400 \mathrm{mg} / \mathrm{kg}$ NS decreased serum BUN level compared to PTU group ( $<<0.05-p<0.01$ Figure 6).

\section{Discussion}

The current study demonstrates that PTU exposure during the neonatal and juvenile periods results in a development of hypothyroidism and negatively influences the renal functions in rats.

The results showed that MDA concentration increased, while total thiols concentration of CAT and SOD activity decreased in renal tissues due to PTUinduced hypothyroidism. These findings are consistent with our previous study, which has shown hypothyroidism induced lipid peroxidation in the brain tissues (Beheshti et al. 2016; Farrokhi et al. 2014). The findings of another study have demonstrated that in hypothyroidism, the MDA level was increased and GSH levels decreased in kidney tissues (Baltaci et al. 2014). On the other hand, it has been well documented that thyroid hormones may influence the function of all body organs and cells. The data presented here indicate how the biochemical markers of the kidney may be affected by the alteration in the level of thyroid hormones in the body following PTU administration. In contrast to these findings, another study has shown that PTU-induced hypothyroidism reduces the oxidative damage in the lung, hepatic, renal, and ileal tissues, probably due to hypo-metabolism, which is associated with a decreased production of reactive oxygen metabolites and enhancement of antioxidant mechanisms (Sener et al. 2006).

Serum creatinine and BUN are markers of glomerular filtration rate (Karimi et al. 2005). Results of this study showed that PTU-induced hypothyroidism increased BUN and creatinine in the serum of rats during neonatal and growth period. Consistent with the results of the present study, in a clinical study, serum creatinine level was elevated in congenitally hypothyroid infants (Asami and Uchiyama 2000). It has also been suggested that screening for hypothyroidism conditions should be considered in patients with unexplained elevations in the serum creatinine (Ponsoye et al. 2013).

Herbal drugs play a key role in the folk medicine due to their protective properties (Iweala et al. 2011; Ahmad et al. 2013; Beheshti et al. 2017). In re- cent years, an attention has been drawn to various plants and plant-derived compounds for the treatment of kidney diseases (Mousavi 2015; Mohebbati et al. 2016). Among the promising medicinal plants, NS, commonly known as Kalonji in India and Pakistan, has been used traditionally for various ailments (Boskabady et al. 2007; Qidwai et al. 2009). NS belongs to the Ranunculaceae family. The seeds of the plant, commonly known as black seeds, have been widely used to protect the health and overcome diseases for centuries in the Middle and Far East countries (GaliMuhtasib et al. 2006). The pharmacological actions of the crude extracts of the seeds and some of their active constituents, e.g. volatile oil and TQ, have been reported to include protection against nephrotoxicity induced by either the disease or chemicals (Ali and Blunden 2003).

In this study, we showed that NS can improve oxidative damage parameters. The facts of this study that NS causes a significant increase in the total thiols concentration, CAT, and SOD activities and decreases MDA in comparison with PTU group, suggest that NS extract might have an antioxidant effect through the improvement of these parameters. The results of the current study confirm the previous findings regarding the protective effects of NS on renal oxidative damage. Many studies have shown that NS have anti-inflammatory effect in various models (Boskabady et al. 2008; Boskabady et al. 2011a; Boskabady et al. 2011b; Boskabady et al. 2011c; Beheshti et al. 2016; Gholamnezhad et al. 2015). It has been demonstrated that NS treatment increases CAT, GSH-Px, and SOD activities in the renal ischemia-reperfusion injury (Mousavi 2015). The results of another study have shown that NS oil may have protective effects against the hepatotoxicity and renal toxicity induced by ethanol through decreasing lipid peroxidation, inflammation, and apoptosis (Pourbakhsh et al. 2014). It has also been demonstrated that NS is useful in ameliorating the signs of gentamycin-induced nephrotoxicity in rats by increasing the total antioxidants and glutathione concentrations in the renal cortex (Ali 2004). NS has also been reported to be able to decrease MDA level, while increased SOD activity and ameliorated the effect of gentamicin on renal tissue (Yaman and Balikci 2010).

Previously, it has been evidenced that renal function parameters were improved by NS therapy. For example, NS was able to decrease the serum creatinine and BUN in cisplatin-induced nephrotoxicity in rats (El Daly 1998). Therefore, findings of our study showed that BUN and creatinine were decreased by NS therapy. Using a renal ischemia-reperfusion in- 
jury model, it has been demonstrated that the serum creatinine, BUN and uric acid levels were increased, which were prevented by NS administration (Mousavi 2015). In another study, NS oil ameliorated the sodium nitrite-induced nephrotoxicity via blocking the oxidative stress and reduced elevation of the serum urea and creatinine induced by sodium nitrite (AlGayyar et al. 2016).

The results of present study also indicate that administration of NS hydroalcoholic extract increased the serum T4 level. It has been previously reported that NS oil, given orally, significantly increases the concentration of T4 and T3 and decreases the TSH in hypothyroid rats in comparison with the control group. It has been suggested that restoration of thyroid parenchyma was related to protection offered by NS oil against hyperplasic changes, well known to be associated with hypothyroid status (Stelios et al. 2007). In many studies, the therapeutic effect of NS oil against PTU-induced hypothyroidism has been attributed to its antioxidant effect (Mahmoud et al. 2002; Nayak and Burman 2006). Thus, it might be suggested that the mechanism of action of the extract, seen in the present study, at least in part, is due to the antioxidant defense mechanism that may protect the thyroid gland against PTU toxicity. In addition, in another study, the effects of TQ on nephrotoxicity induced by cisplatin has been investigated and showed that cisplatin decreased the hepatic expression nuclear levels of NF-E2-related factor-2 (Nrf2) and the heme oxygenase-1 (HO-1). TQ administration decreased the cisplatin nephrotoxicity by increasing the levels of Nrf-2 and HO-1 and reducing the levels of
NF- $\kappa B$ (Ulu et al. 2013). These results of the present study indicate another possible mechanism of NS action. However, this issue needs further investigations.

The responsible component(s) for the beneficial effects of the plant extract was not determined in the present study, but in a previous study, which has been done in our laboratory. TQ has been reported as a main component of the plant extract (Seghatoleslam et al 2015). Therefore, the beneficial effects of the plant extract, which was seen in the present study, might be due to TQ. In supporting to this idea, TQ has also been previously reported to have some beneficial effects on renal functions in animal models such as ischemic renal injury (Hammad and Lubbad 2016), diabetic renal impairment function (Al-Trad et al 2016) and gentamycin-induced renal failure (Samarghandian et al 2015). However, this issue requires further investigations.

\section{Conclusion}

The results of present study showed that NS hydroalcoholic extract may improve the renal function in PTU-induced hypothyroid rats during the neonatal and juvenile periods, which was accompanied by an improvement of renal tissues oxidative stress status.

\section{Acknowledgments}

The authors would like to thank the Vice Presidency of Research of Mashhad University of Medical Sciences for their financial support.

\section{References}

Aebi HE. Catalase. In B. HU (Ed.), Methods in Enzymatic Analysis (pp. 276-286), New York, Academic Press, 1993. Ahmad A, Husain A, Mujeeb M, Khan SA, Najmi AK, Siddique NA, Anwar F. A review on therapeutic potential of Nigella sativa: A miracle herb. Asian Pac J Trop Biomed 3, 337-352, 2013.

Al-Gayyar MM, Hassan HM, Alyoussef A, Abbas A, Darweish MM, El-Hawwary AA. Nigella sativa oil attenuates chronic nephrotoxicity induced by oral sodium nitrite: Effects on tissue fibrosis and apoptosis. Redox Rep 21, 50-60, 2016.

Al-Hader A, Aqel M, Hasan Z. Hypoglycemic effects of the volatile oil of Nigella sativa seeds. Pharm Biol 31, 96-100, 1993.

Al-Trad B, Al-Batayneh K, El-Metwally S, Alhazimi A, Ginawi I, Alaraj M, Alkofahi E, Aljumaili O, Kosba A. Nigella sativa oil and thymoquinone ameliorate albuminuria and renal extracellular matrix accumulation in the experimental diabetic rats. Eur Rev Med Pharmacol Sci 20, 2680-2688, 2016.

Ali B, Blunden G. Pharmacological and toxicological properties of Nigella sativa. Phytother Res 17, 299-305, 2003.

Ali BH. The effect of Nigella sativa oil on gentamicin nephrotoxicity in rats. Am J Chin Med 32, 49-55, 2004.

Asami T, Uchiyama M. Elevated serum creatinine levels in infants with congenital hypothyroidism: reflection of decreased renal function? Acta Paediatr 89, 1431-1434, 2000.

Baltaci AK, Mogulkoc R, Ayyildiz M, Kafali E, Koyuncuoglu T. Lipid peroxidation in kidney and testis tissues in experimental hypothyroidism: the role of zinc. Bratisl Lek Listy 115, 498-501, 2014. 
BeheshtiF,KhazaeiM,HosseiniM.NeuropharmacologicaleffectsofNigellasativa.AvicennaJPhytomed6,104-116,2016. Beheshti F, Hosseini M, Shafei MN, Soukhtanloo M, Ghasemi S, Vafaee F, Zarepoor L. The effects of Nigella sativa extract on hypothyroidism-associated learning and memory impairment during neonatal and juvenile growth in rats. Nutr Neurosci 20, 49-50, 2017.

Boskabady MH, Shirmohammadi B, Jandaghi P, Kiani S. Possible mechanism(s) for relaxant effect of aqueous and macerated extracts from Nigella sativa on tracheal chains of guinea pig. BMC Pharmacol 4, 3, 2004.

Boskabady MH, Javan H, Sajady M, Rakhshandeh H. The possible prophylactic effect of Nigella sativa seed extract in asthmatic patients. Fundam Clin Pharmacol 21, 559-566, 2007.

Boskabady MH, Keyhanmanesh R, Saadatloo MA. Relaxant effects of different fractions from Nigella sativa L. on guinea pig tracheal chains and its possible mechanism (s). Indian J Exp Biol 46, 805-810, 2008.

Boskabady MH, Keyhanmanesh R, Khameneh S, Doostdar Y, Khakzad MR. Potential immunomodulation effect of the extract of Nigella sativa on ovalbumin sensitized guinea pigs. J Zhejiang Univ Sci B 12, 201-209, 2011 a.

Boskabady MH, Keyhanmanesh R, Khamneh S, Ebrahimi MA. The effect of Nigella sativa extract on tracheal responsiveness and lung inflammation in ovalbumin-sensitized guinea pigs. Clinics 66, 879-887, $2011 \mathrm{~b}$.

Boskabady MH, Vahedi N, Amery S, Khakzad MR. The effect of Nigella sativa alone, and in combination with dexamethasone, on tracheal muscle responsiveness and lung inflammation in sulfur mustard exposed guinea pigs. Journal of ethnopharmacology 137, 1028-1034, 2011c.

Cooper DS. Antithyroid drugs. N Engl J Med 311, 1353-1362, 1984.

Derubertis FR, Michelis MF, Bloom ME, Mintz DH, Field JB, Davis BB. Impaired water excretion in myxedema. Am J Med 51, 41-53, 1971.

El-Dakhakhny M, Mady N, Lembert N, Ammon HP. The hypoglycemic effect of Nigella sativa oil is mediated by extrapancreatic actions. Planta Med 68, 465-466, 2002.

El Daly ES. Protective effect of cysteine and vitamin E, Crocus sativus and Nigella sativa extracts on cisplatin-induced toxicity in rats. J Pharm Belg 53, 87-93, 1998.

El-Kadi A, Kandil O. The black seed (Nigella sativa) and immunity: its effect on human T cell subset. Fed Proc 46, 1222-1226, 1987.

Ellman GL. Tissue sulfhydryl groups. Arch Biochem Biophys 82, 70-77, 1959.

Farrokhi E, Hosseini M, Beheshti F, Vafaei F, Hadjzadeh MA, Dastghaib SS. Brain tissues oxidative damage as a possible mechanism of deleterious effects of propylthiouracil-induced hypothyroidism on learning and memory in neonatal and juvenile growth in rats. Basic Clin Neurosci 5, 285-294, 2014.

Fumarola A, Di Fiore A, Dainelli M, Grani G, Calvanese A. Medical treatment of hyperthyroidism: state of the art. Exp Clin Endocrinol 118, 678, 2010.

Gali-Muhtasib H, El-Najjar N, Schneider-Stock R. The medicinal potential of black seed (Nigella sativa) and its components. In M. a. A. A. Khan (Ed.), Lead Molecules from Natural Products: Discovery and New Trends[M] (pp. 133-153): Elsevier BV. 2006.

Gholamnezhad Z, Keyhanmanesh R, Boskabady MH. Anti-inflammatory, antioxidant, and immunomodulatory aspects of Nigella sativa for its preventive and bronchodilatory effects on obstructive respiratory diseases: A review of basic and clinical evidence. J Funct Foods 17, 910-927, 2015.

Hadjzadeh MA, Khoei A, Hadjzadeh Z, Parizady M. Ethanolic extract of nigella sativa L seeds on ethylene glycolinduced kidney calculi in rats. Urol J 4, 86-90, 2007.

Hammad FT, Lubbad L.The effect of thymoquinone on the renal functions following ischemia-reperfusion injury in the rat. Int J Physiol Pathophysiol Pharmacol 8, 152-159, 2016.

Hosseini M, Hadjzadeh MA, Derakhshan M, Havakhah S, Rassouli FB, Rakhshandeh H, Saffarzadeh F. The beneficial effects of olibanum on memory deficit induced by hypothyroidism in adult rats tested in Morris water maze. Arch Pharm Res 33, 463-468, 2010.

Hosseini M, Pourganji M, Khodabandehloo F, Soukhtanloo M, Zabihi H. Protective effect of L-arginine against oxidative damage as a possible mechanism of its beneficial properties on spatial learning in ovariectomized rats. Basic Clin Neurosci 3, 36-44, 2012.

Houghton PJ, Zarka R, de las Heras B, Hoult JR. Fixed oil of Nigella sativa and derived thymoquinone inhibit eicosanoid generation in leukocytes and membrane lipid peroxidation. Planta Med 61, 33-36, 1995.

Iweala E, Obichi I, Omotosho O. Biochemical and histological responses of hepatotoxic rats fed Musa paradisiaca L. supplemented diet. Int J Pharmacol 4, 471-477, 2011.

Javanbakht J, Hobbenaghi R, Hosseini E, Bahrami A M, Khadivar F, Fathi S, Hassan MA. Histopathological investigation of neuroprotective effects of Nigella sativa on motor neurons anterior horn spinal cord after sciatic nerve crush in rats. Pathol Biol (Paris) 61, 250-253, 2013. 
Karimi G, Ramezani M, Tahoonian Z. Cisplatin nephrotoxicity and protection by milk thistle extract in rats. Evid Based Complement. Alternat Med 2, 383-386, 2005.

Kanter M. Nigella sativa and derived thymoquinone prevents hippocampal neurodegeneration after chronic toluene exposure in rats. Neurochem Res 33, 579, 2008.

Katyare SS, Bangur CS, Howland JL. Is respiratory activity in the brain mitochondria responsive to thyroid hormone action? A critical reevaluation. Biochem J 302, 857-860, 1994.

Keyhanmanesh R, Boskabady MH, Khamneh S, Doostar Y. Effect of thymoquinone on the lung pathology and cytokine levels of ovalbumin-sensitized guinea pigs. Pharmacol Rep 62, 910-916, 2010.

Khan N, Sharma S, Sultana S. Nigella sativa (black cumin) ameliorates potassium bromate-induced early events of carcinogenesis: diminution of oxidative stress. Hum Exp Toxicol 22, 193-203, 2003.

Khodabandehloo F, Hosseini M, Rajaei Z, Soukhtanloo M, Farrokhi E, Rezaeipour M. Brain tissue oxidative damage as a possible mechanism for the deleterious effect of a chronic high dose of estradiol on learning and memory in ovariectomized rats. Arq Neuropsiquiatr 71, 313-319, 2013.

Madesh M, Balasubramanian KA. Microtiter plate assay for superoxide dismutase using MTT reduction by superoxide. Indian J Biochem Biophys 35, 184-188, 1998.

Mahmoud M, El-Abhar H, Saleh S. The effect of Nigella sativa oil against the liver damage induced by Schistosomamansoniinfection in mice. J Ethnopharmacol 79, 1-11, 2002.

Martinez B, del Hoyo P, Martin MA, Arenas J, Perez-Castillo A, Santos A. Thyroid hormone regulates oxidative phosphorylation in the cerebral cortex and striatum of neonatal rats. J Neurochem 78, 1054-1063, 2001.

Mohebbati R, Shafei MN, Soukhtanloo M, Mohammadian Roshan N, Khajavi Rad A, Anaeigoudari A, Beheshti F. Adriamycin-induced oxidative stress is prevented by mixed hydro-alcoholic extract of Nigella sativa and Curcuma longa in rat kidney. Avicenna J Phytomed 6, 86-94, 2016.

Moses AM, Scheinman SJ. The kidneys and electrolyte metabolism in hypothyroidism. In : Braveman LE, Utiger RD, eds. Werner and Ingbar's The Thyroid. 7th ed. Philadelphia, PA: Lippincott-Raven Publishers; 812-815, 1996.

Mousavi G. Study on the effect of black cumin (Nigella sativa Linn.) on experimental renal ischemia-reperfusion injury in rats. Acta Cir Bras 30, 542-550, 2015.

Nakahama H, Nakamura H, Kitada O, Sugita M. Chronic drug-induced tubulointerstitial nephritis with renal failure associated with propylthiouracil therapy. Nephrol Dial Transplant 14, 1263-1265, 1999.

Nayak B, Burman K. Thyrotoxicosis and Thyroid Storm. Endocrinol Metab Clin North Am 35, 663-686, 2006.

Ponsoye M, Paule R, Gueutin V, Deray G, Izzedine H. [Kidney and thyroid dysfunction]. Nephrol Ther 9, 13-20, 2013.

Pourbakhsh H, Taghiabadi E, Abnous K, Hariri AT, Hosseini SM, Hosseinzadeh H. Effect of Nigella sativa fixed oil on ethanol toxicity in rats. Iran J Basic Med Sci 17, 1020-1031, 2014.

Prasad GV, Bastacky S, Johnson JP. Propylthiouracil-induced diffuse proliferative lupus nephritis: review of immunological complications. J Am Soc Nephrol 8, 1205-1210, 1997.

Qidwai W, Hamza HB, Qureshi R, Gilani A. Effectiveness, safety, and tolerability of powdered Nigella sativa (kalonji) seed in capsules on serum lipid levels, blood sugar, blood pressure, and body weight in adults: results of a randomized, double-blind controlled trial. J Altern Complement Med 15, 639-644, 2009.

Reinhart SC, Moses AM, Cleary L, Scheinman SJ. Acute interstitial nephritis with renal failure associated with propylthiouracil therapy. Am J Kidney Dis 24, 575-577, 1994.

Salem ML. Immunomodulatory and therapeutic properties of the Nigella sativa L. seed. Int Immunopharmacol 5, 1749-1770, 2005.

Samarghandian S, Azimi-Nezhad M, Mehrad-Majd H, Mirhafez SR. Thymoquinone Ameliorates Acute Renal Failure in Gentamicin-Treated Adult Male Rats. Pharmacology 96, 112-117, 2015.

Sarandol E, Tas S, Dirican M, Serdar Z. Oxidative stress and serum paraoxonase activity in experimental hypothyroidism: effect of vitamin E supplementation. Cell Biochem Funct 23, 1-8, 2005.

Sener G, Kabasakal L, Atasoy B M, Erzik C, Velioglu-Ogunc A, Cetinel S, Yegen BC. Propylthiouracil-induced hypothyroidism protects ionizing radiation-induced multiple organ damage in rats. J Endocrinol 189, 257-269, 2006.

Seghatoleslam M, Alipour F, Shafieian R, Hassanzadeh Z, Edalatmanesh MA, Sadeghnia HR, Hosseini M. The effects of Nigella sativa on neural damage after pentylenetetrazole induced seizures in rats. J Tradit Complement Med 6, 262-268, 2015.

Singh PA, Bobby Z, Selvaraj N, Vinayagamoorthi R. An evaluation of thyroid hormone status and oxidative stress in undialyzed chronic renal failure patients. Indian J Physiol Pharmacol 50, 279, 2006.

Stelios F, George P, Agathocles T. The role of iodine in the evolution of thyroid disease in Greece: from endemic goiter to thyroid autoimmunity. Horm 6, 25-35, 2007. 
Ulu R, Dogukan A, Tuzcu M, Gurel A, Muqbil I. Modulation of Nrf2/HO-1 by thymoquinone during cisplatininduced nephrotoxicity. Turk Neph Dial Transpl 22,182-187, 2013.

Yaman I, Balikci E. Protective effects of Nigella sativa against gentamicin-induced nephrotoxicity in rats. Exp Toxicol Pathol 62,183-190, 2010. 